\title{
Dreno de sucção fechado em mastectomias unilaterais totais em cadelas ${ }^{1}$
}

\author{
Carina Freccia ${ }^{2 *}$, Ademar L. Dallabrida ${ }^{4}$, Ádson Costa ${ }^{2}$, Bruna D.C. Regalin ${ }^{4}$, \\ Felipe Comassetto ${ }^{4}$, Helena M. Cardoso ${ }^{4}$, Marzia Antonelli ${ }^{5}$ e Nilson Oleskovicz ${ }^{3}$
}

\begin{abstract}
Freccia C., Dallabrida A.L., Costa Á., Regalin B.D.C., Comassetto F., Cardoso H.M., Antonelli M. \& Oleskovicz N. 2018. [Closed suction drain in total unilateral mastectomy in bitches.] Dreno de sucção fechado em mastectomias unilaterais totais em cadelas. Pesquisa Veterinária Brasileira 38(7):1412-1422. Programa de Pós-Graduação em Ciência Animal, Universidade do Estado de Santa Catarina, Av. Luiz de Camões 2090, Conta Dinheiro, Lages, SC 88520-000, Brazil. E-mail: carinafreccia@hotmail.com

The aim of this study was to evaluate the use of closed suction drain in surgical wounds of total unilateral mastectomy in dogs. Eighteen dogs were used with an average weight of $14.87 \pm 9.29 \mathrm{~kg}$, average age $9.34 \pm 2.68$ years, from the hospital routine, which were selected through clinical and oncological evaluation. The animals were divided into two groups: Conventional (CG, n=9) which underwent total unilateral mastectomy surgery without drain and Drain group (DG, n=9) which underwent complete unilateral mastectomy with placement closed suction drain (Biovácuo ${ }^{\circledR}$ ). The diameter of the drain was determined according to the animal weight. Five evaluations were performed during the postoperative period: clinical evaluation of the animals daily through the heart rate (HR), respiratory rate (RR), rectal temperature (RT), color of mucous membranes, capillary refill time (CRT), degree of dehydration, blood count, chemistry profile (urea, creatinine, cholesterol, triglycerides and glucose); qualitative assessment of the drain; qualitative assessment of the surgical wound, is also being held on 14 and 30 days for the presence or absence of exudate, edema, skin integrity, dehiscence, necrosis and scarring; quantitative evaluation of the drained fluid; qualitative assessment of fluid drained, as the cellularity type and cell morphology. Surgical time was recorded in both groups. There were an increase in average values of density, neutrophils, lymphocytes, and increased fibrinogen median value of drained fluid in 72 hours compared to 24 hours in DG group. There was an increase of exudate within 24, 48 and 72 hours in DG when compared to GC. There was an increase in the volume of drained fluid in 60 and 72 hours compared to 12 hours in DG. There was a reduction in the average value of red blood cells within 72 hours from baseline in DG group. There was an increase in average hemoglobin and hematocrit in 24 hours in the control group compared to the DG. There was an increase in the average value of neutrophils targeted at baseline in DG when compared to CG. It follows that, the closed suction drain placement technique presents more exudate. It is recommended that the drain vacuum is redone 12 in 12 hours, initially being performed 6 hours after surgery. The closed suction drain does not generate additional discomfort to the patient; it is recommended that it be removed 72 hours after the surgery, when the fluid production decreases, but even so some individuals may present seroma formation in the late postoperative.
\end{abstract}

INDEX TERMS: Mastectomy, bitches, breast cancer, drainage, seroma, dogs, surgery.

\footnotetext{
${ }^{1}$ Recebido em 30 de maio de 2017.

Aceito para publicação em 12 de junho de 2017.

${ }^{2}$ Mestranda em Ciência Animal, Universidade do Estado de Santa Catarina (UDESC), Av. Luiz de Camões 2090, Conta Dinheiro, Lages, SC 88520-000, Brasil. *Autor para correspondência: carinafreccia@hotmail.com

${ }^{3}$ Docente do Departamento de Medicina Veterinária, Centro de Ciências Agroveterinárias (CAV), Universidade do Estado de Santa Catarina (UDESC), Av. Luiz de Camões 2090, Conta Dinheiro, Lages, SC 88520-000.

${ }^{4}$ Doutorando em Ciência Animal, Centro de Ciências Agroveterinárias (CAV), Universidade do Estado de Santa Catarina (UDESC), Av. Luiz de Camões 2090, Conta Dinheiro, Lages, SC 88520-000.

${ }^{5}$ Bolsista de Iniciação Científica de Medicina Veterinária, Centro de Ciências Agroveterinárias (CAV), Universidade do Estado de Santa Catarina (UDESC), Av. Luiz de Camões 2090, Conta Dinheiro, Lages, SC 88520-000.
}

RESUMO.- 0 objetivo deste estudo foi avaliar a utilização de dreno de sucção fechado em feridas cirúrgicas de mastectomias unilaterais totais em cadelas. Foram utilizadas 18 cadelas com peso médio de $14,87 \pm 9,29 \mathrm{~kg}$, idade média $9,34 \pm 2,68$ anos, provenientes da rotina hospitalar, as quais foram selecionadas por meio de avaliação clínica e oncológica. Os animais foram alocados em dois grupos: Convencional ( $\mathrm{GC}, \mathrm{n}=9$ ) que foram submetidas à cirurgia de mastectomia unilateral total, sem colocação de dreno e grupo Dreno (GD, n=9) que foram submetidas à mastectomia unilateral total com colocação do dreno de sucção fechado $\left(\right.$ Biovácuo ${ }^{\circledR}$ ), sendo o diâmetro do 
dreno determinado conforme peso do animal. Foram realizadas cinco avaliações durante o período pós-operatório: avaliação clínica diária dos animais através da frequência cardíaca (FC), frequência respiratória $(f)$, temperatura retal (TR), coloração de mucosas, tempo de preenchimento capilar (TPC), grau de desidratação, hemograma, perfil bioquímico (ureia, creatinina, colesterol, triglicérides e glicose); avaliação qualitativa do dreno; avaliação qualitativa da ferida cirúrgica, sendo esta também realizada em 14 e 30 dias quanto à presença ou não de exsudato, edema, integridade da pele, deiscência, necrose e fibrose cicatricial; avaliação quantitativa do fluido drenado e avaliação qualitativa do fluido drenado, quanto à celularidade, tipo e morfologia celular. Houve aumento dos valores médios de densidade, neutrófilos, linfócitos, e aumento do valor de mediana de fibrinogênio do fluido drenado em 72 horas em relação às 24 horas no grupo GD. Ocorreu aumento do exsudato em 24, 48 e 72 horas no GD quando comparado ao GC. Houve aumento do volume de fluido drenado em 60 e 72 horas em relação às 12 horas no grupo GD. Houve redução do valor médio de eritrócitos em 72 horas em relação ao basal no grupo GD. Observou-se aumento nos valores médios de hemoglobina e hematócrito em 24 horas no grupo GC quando comparado ao GD. Houve aumento no valor médio de neutrófilos segmentados no basal no GD quando comparado ao GC. Conclui-se que a técnica de colocação de dreno de sucção fechado apresenta maior teor de exsudato. Recomenda-se que o vácuo do dreno seja refeito de 12 em 12 horas, sendo inicialmentrealizado 6 horas após o término da cirurgia. 0 dreno de sucção fechado não gera desconforto adicional ao paciente; recomenda-se que o mesmo seja removido 72 horas após o término da cirurgia, quando a produção de fluido diminui, porém mesmo assim alguns indivíduos podem apresentar formação de seroma no pós-operatório tardio.

TERMOS DE INDEXAÇÃO: Dreno de sucção, mastectomia, cadelas, neoplasia mamária, drenagem, seroma, cirurgia.

\section{INTRODUÇÃO}

A prevalência de neoplasias é considerada por alguns autores a maior causa de morte (Sorenmo et al. 2009), sendo que os tumores da glândula mamária correspondem ao tipo de neoplasia mais frequente em cadelas (Cassali et al. 2011). O tratamento cirúrgico é considerado o padrão ouro para a maioria dos tipos de tumores mamários, exceto para tumores inoperáveis altamente metastáticos e para maioria dos carcinomas mamários inflamatórios (Sleeckx et al. 2011).

A síntese das mastectomias pode ser a parte mais desafiadora do procedimento cirúrgico, sendo que a eliminação do espaço morto e o manejo da tensão na linha de incisão são os pontos mais importantes (Withrow 2013). A formação de espaço morto excessivo durante a cirurgia, ou falha em reduzi-lo adequadamente, principalmente quando associada ao resultado de dissecção excessiva ou remoção de uma grande área de tecido, podem levar a formação de seroma (Williams \& Moores 2013). Sendo esta a complicação pós-operatória mais frequente em mastectomias e cirurgias axilares de mulheres, com uma incidência de 3 a 85\% (Kumar et al. 1995). Em cadelas, as complicações associadas às mastectomias incluem formação de seroma, infecção da ferida, deiscência, necrose isquêmica, auto-mutilação, perda sanguínea, edema de membros pélvicos e recidiva tumoral (Harvey 1996).

Na espécie humana, os drenos servem para prevenir ou evacuar acúmulos de fluidos ou gás (Dougherty \& Simmons 1992), podendo ser classificados em passivos ou ativos, os passivos dependem da ação capilar e do fluxo gravitacional do dreno, que deve ser exteriorizado na parte ventral da ferida (Williams \& Moores 2013), enquanto que os ativos requerem vácuo em circuito fechado. Os drenos de sucção fechados estabelecem um gradiente de pressão entre a ferida e o meio externo, e acredita-se que por serem sistemas fechados reduzam o risco de infecção hospitalar, além de serem mais efetivos na remoção de líquidos em comparação aos drenos passivos (Dougherty \& Simmons 1992, Williams \& Moores 2013). Em mulheres os drenos de sucção fechados são utilizados rotineiramente após mastectomias para reduzir ou prevenir a formação de seroma, sendo que sua colocação é alvo de muitas investigações científicas gerando muitas controvérsias em relação à prevenção de seroma (Agrawal et al. 2006). Desta forma, o objetivo do estudo foi avaliar a utilização de drenos de sucção fechados em relação aos benefícios para diminuição ou manejo de seromas em feridas pós-operatórias de mastectomias em cadelas, verificar o grau de desconforto para o paciente, bem como comparar tempos cirúrgicos entre as duas técnicas e avaliar qualitativamente o fluido drenado.

\section{MATERIAL E MÉTODOS}

Este estudo foi aprovado pelo Comitê de Ética e Experimentação Animal (CETEA) da Instituição de origem, protocolo número 01.60.14. Foram

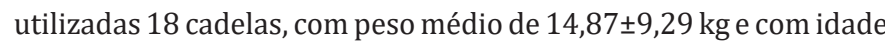
média 9,34 $\pm 2,68$ anos, provenientes da rotina do Hospital Veterinário as quais foram encaminhadas para mastectomia unilateral total. Uma semana antes do estudo foi realizada avaliação clínica basal com frequência cardíaca (FC), frequência respiratória $(f)$, temperatura retal $\left(\mathrm{T}^{\circ} \mathrm{R}\right)$, tempo de preenchimento capilar (TPC), coloração de mucosas, exames complementares como hemograma, bioquímica sérica com função renal (ureia e creatinina) e função hepática (glicose, triglicérides e colesterol), radiografia torácica (projeção ventrodorsal, látero-lateral direita e esquerda), ultrassonografia abdominal e eletrocardiograma. Exames complementares além de fazerem parte da rotina oncológica de estadiamento da neoplasia mamária na pesquisa de metástases, também tinham por objetivo a investigação de outras comorbidades que pudessem influenciar no estudo, como cardiopatias, distúrbios urinários, distúrbios hepáticos e renais, patologias reprodutivas e infecções, como tumores ulcerados. Tais comorbidades foram tratadas com terapêutica inerente a cada caso e assim estes pacientes excluídos do estudo. Os animais foram internados no dia anterior ao estudo para ambientação, sendo mantidos durante todo período pré e pós-operatório em sala apropriada, sem contato com outros animais ou elementos estressantes, receberam água ad libitum e fornecimento de ração premium com ração pastosa três vezes ao dia.

Um dia antes do início do estudo, as cadelas foram tricotomizadas nas regiões das veias cefálicas esquerda e direita, artérias podais, região abdominal e torácica ventral. Passaram por jejum alimentar de 
10 horas e restrição hídrica de 6 horas. No dia da cirurgia, os animais foram submetidos à medicação pré-anestésica com $0,5 \mathrm{mg} / \mathrm{kg}$ de morfina (Dimorf ${ }^{\circledR}$, Sulfato de morfina $10 \mathrm{mg} / \mathrm{mL}$, Cristália, Itapira/SP, Brasil) e $0,02 \mathrm{mg} / \mathrm{kg}$ de acepromazina (Acepran ${ }^{\circledR}$, Acepromazina 0,2\%, Vetnil, Louveiros/SP, Brasil), ambas por via intramuscular. Posteriormente foi realizada venopunção cefálica para inserção de um cateter venoso calibre 22G (Cateter Intravascular Periférico 22 $\mathrm{G}^{\circledR}$, Jelco, Smiths Medical do Brasil Produtos Hospitalares Ltda., São Paulo/SP, Brasil), sendo induzidos à anestesia geral com $4 \mathrm{mg} / \mathrm{kg}$ de propofol (Propotil $^{\circledR}$, Propofol 1\%, Dongkook Pharm. Co. Ltd., BioChimico Indústria Farmacêutica Ltda., Rio de Janeiro/RJ, Brasil).

Ato contínuo foram intubados com sonda endotraqueal de tamanho compatível com o animal e mantidos em anestesia geral inalatória com isofluorano (Isoforine ${ }^{\circledR}$ isoflurano, Cristália Prod. Quím. Farm. Ltda, Itapira/SP, Brasil) a 1,3 V\% diluído em oxigênio à 100\%. Após indução anestésica, foi administrado bolus intravenoso de $2,5 \mathrm{mg} / \mathrm{kg}$ de cetamina $\left(\right.$ Vetaset $^{\circledR}$, Cloridrato de Cetamina 10\%, Fort Dodge Saúde Animal, Campinas/SP, Brasil), seguida da infusão de $10 \mathrm{mcg} / \mathrm{kg} / \mathrm{min}$ ou $2,5 \mathrm{mcg} / \mathrm{kg}$ de fentanil seguida da infusão de $10 \mathrm{mcg} / \mathrm{kg} / \mathrm{h}$ (Fentanyl ${ }^{\circledR}$, Citrato de fentanila $50 \mathrm{mcg} / \mathrm{ml}$, Billi Farmacêutica Ltda, São Paulo/SP, Brasil), estudo paralelo. Para antibioticoterapia profilática foi utilizado cefalotina (Keflin ${ }^{\circledR}$, Cefalotina sódica 1g, Antibióticos do Brasil Ltda, Cosmópolis/SP, Brasil) na dose de $30 \mathrm{mg} / \mathrm{kg}$, via intravenosa 30 minutos antes do procedimento cirúrgico.

Os procedimentos cirúrgicos foram realizados pelo mesmo cirurgião e o tempo foi cronometrado desde a incisão de pele até o término da dermorrafia. No início da cirurgia, os animais foram posicionados em decúbito dorsal e foi realizada antissepsia com álcool $70 \%$ e iodo povidine tópico. Neste momento, as 18 cadelas foram alocadas aleatoriamente em dois grupos $(n=9)$ sendo submetidas à mastectomia unilateral total convencional (GC) ou submetidas à mastectomia unilateral total com utilização de dreno de sucção fechado (GD) (Biovácuo ${ }^{\circledR}$, Biotec Produtos Hospitalares, Mairiporã/SP, Brasil). Os dois grupos foram submetidos inicialmente à mastectomia da mesma forma, com incisão elíptica circundando a cadeia mamária acometida desde a mama torácica cranial até a mama inguinal, divulsão romba cuidadosa entre tecido subcutâneo e fáscia abdominal e músculo peitoral com tesoura, excisão do tecido glandular, hemostasia de pequenos vasos com eletrocoagulação e de grandes vasos (artérias epigástricas superficiais cranial e caudal) com ligaduras com náilon monofilamentoso 3-0 (Procare ${ }^{\circledR}$, Nylon Monofilamento Preto, China) seguida da lavagem do leito cirúrgico com solução de Ringer-Lactato aquecida (Solução Ringer com Lactato ${ }^{\circledR}$, Fresenius Kabi Brasil Ltda., Barueri/SP), sendo observado cuidadosamente se todo tecido mamário havia sido completamente removido.

A síntese no grupo GC ocorreu no subcutâneo com pontos interrompidos simples e em alguns locais do subcutâneo com sutura caminhante (walking suture), e na dermorrafia com pontos interrompidos simples, ambos com náilon monofilamentoso agulhado 2-0 ou 3-0, conforme tamanho do animal. Enquanto, que no grupo GD após lavagem do leito cirúrgico foi colocado dreno de sucção fechado, composto por tubo siliconado multiperfurado radiopaco em toda extensão do leito cirúrgico (Fig.1A). A fixação do dreno na pele ocorreu em região crânio-medial ao sítio cirúrgico com ponto bailarina com náilon monofilamentoso (Fig.1B). A síntese no grupo GD subcutâneo foi realizada em padrão contínuo simples, e na dermorrafia com pontos interrompidos simples, ambos com náilon monofilamentoso agulhado 2-0 ou 3-0, conforme tamanho do animal. A escolha do diâmetro do dreno foi determinada conforme peso do animal, sendo em animais abaixo de $8 \mathrm{~kg}$ utilizado cânula de 3,2mm, animais de 8 a $20 \mathrm{~kg}$ cânula de 4,8mm e animais acima de $20 \mathrm{~kg}$ cânula de $6,4 \mathrm{~mm}$, sendo que nos animais do grupo GD foi acoplado ao tubo siliconado um reservatório de $600 \mathrm{~mL}$ onde a pressão negativa do sistema de vácuo se mantinha quando o reservatório permanecia pressionado (Fig.1C).

No GD o vácuo foi estabelecido após o término da dermorrafia, pressionando-se ao máximo o reservatório sanfonado e fechando-se a válvula do reservatório, sendo neste momento o clamp (ou pinça corta-fluxo) aberto para início do processo de drenagem. 0 primeiro vácuo foi refeito em 6 horas após o término da cirurgia, sendo este restabelecido a cada 12 horas, até a retirada do dreno. Após o término do procedimento realizou-se confecção de bandagem compressiva e colocação de roupa cirúrgica em ambos os grupos. Em seguida no GD, foi colocado suporte para acomodação do dreno, o qual permanecia preso na região lombar, semelhante a um colete (Fig.1D). Ao término da cirurgia administrou-se $0,2 \mathrm{mg} / \mathrm{Kg}$ de meloxicam em todos os animais (Maxicam ${ }^{\circledR}$ 0,2\%, Ourofino Saúde Animal, Cravinhos/SP, Brasil) por via subcutânea. Todos os tumores foram coletados e enviados ao laboratório de patologia animal da instituição, para diagnóstico histopatológico, sendo que os animais que apresentavam mais de um tumor na cadeia mamária, as mamas foram coletadas separadamente, pois estas poderiam apresentar diagnósticos histopatológicos diferentes dentro da mesma cadeia. No período pós-operatório administrou-se meloxicam (Maxicam ${ }^{\circledR}$, Meloxicam 0,2\%, Ourofino Saúde Animal, Cravinhos/SP, Brasil) 0,1mg/kg SID via subcutânea, a partir do segundo dia, por 3 dias, dipirona (Novalgina ${ }^{\circledR}$, Dipirona monohidratada 500mg, Medley, Campinas/SP, Brasil) $25 \mathrm{mg} / \mathrm{kg}$ TID via oral por 5 dias, tramadol $\left(\right.$ Tramal $^{\circledR}$, Cloridrato de tramadol 50mg, Laboratótio Teuto, Anápolis/G0, Brasil) 7mg/kg TID via oral por 5 dias e cefalexina $30 \mathrm{mg} / \mathrm{kg}$ (Celesporin ${ }^{\circledR}$, Ourofino Saúde Animal Ltda., Cravinhos/SP, Brasil) BID, por via oral por 7 dias. Durante o internamento todos os animais permaneceram de roupa cirúrgica para evitar auto-mutilações, contudo no grupo GD, além da roupa cirúrgica os animais permaneceram com suporte (colete) para acomodação do dreno e colar elisabetano, para proporcionar mobilidade e conforto para o mesmo e evitar remoção precoce do dreno, sendo que o colar elisabetano era removido apenas durante as avaliações clínicas e de dor e para realização de trocas de curativos.

Durante as 72 horas de pós-operatório, em intervalos de 24 horas, foram realizadas as seguintes avaliações respeitando-se a ordem: avaliação clínica do paciente, avaliação qualitativa do dreno (no grupo GD), avaliação qualitativa da ferida cirúrgica, avaliação quantitativa e qualitativa do fluido drenado, quando presente.

Avaliação clínica do paciente. Através de exame físico completo com $\mathrm{FC}, f$, TR, TPC, coloração de mucosas e grau de desidratação, coletas de sangue para análise hematológica em 24 e 72 horas e para análise do perfil bioquímico (ureia, creatinina, glicose, triglicérides e colesterol) em 72 horas. A análise hematológica objetivou comparar a resposta inflamatória entre os grupos, enquanto o perfil bioquímico teve por objetivo monitoramento das funções renais e hepáticas.

Avaliação qualitativa do dreno. Todas as avaliações foram realizadas pelos mesmos dois cirurgiões experientes, sendo avaliado o grau de desconforto na presença do dreno, observando-se o comportamento do animal a cada 12 horas, conforme escala modificada de Demaria et al. (2011), sendo 0 - nenhum desconforto, 1 - moderada irritação (tenta remover o dreno, "vira a cabeça"), 2 - moderadamente doloroso ("uiva" ou recua ao contato) e 3 - dor acentuada (grita, tenta morder ou fugir). Após esta avaliação o vácuo era restabelecido no reservatório, o tempo de internamento dos 


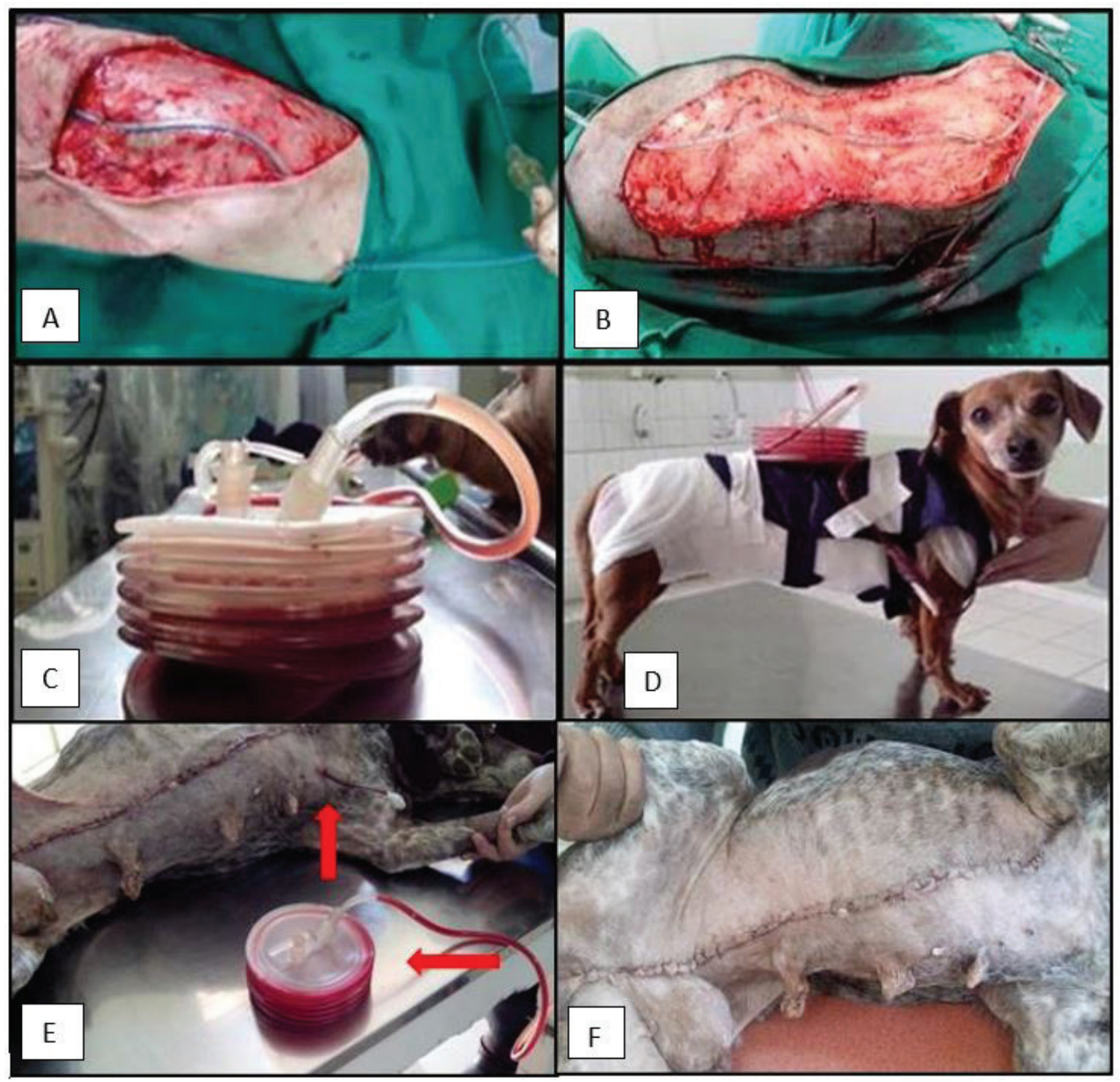

Fig.1. (A) Colocação do dreno de sucção fechado na extensão do leito cirúrgico e saída do dreno em região crânio-medial ao sítio cirúrgico, em cadela submetida à mastectomia unilateral total. (B) Fixação do dreno na pele em região crânio-medial com ponto bailarina (observa-se seta), em cadela submetida à mastectomia unilateral total. (C) Dreno de sucção fechado (cânula de 4,8mm) com reservatório pressionado para manutenção do vácuo e drenagem do líquido subcutâneo. (D) Colocação de roupa cirúrgica e suporte para acomodação do dreno, após cirurgia de mastectomia unilateral total em cadela. (E) Ferida cirúrgica de cadela após 48 horas da realização de mastectomia unilateral total pela técnica com colocação de dreno de sucção fechado (GD). Observa-se presença de exsudato em cânula e reservatório (setas). (F) Ferida cirúrgica de cadela após 14 dias da realização de mastectomia unilateral total pela técnica de colocação de dreno de sucção fechado (GD).

dois grupos foi de 72 horas, sendo que no grupo GD este coincidiu com o momento de retirada do dreno.

Avaliação qualitativa da ferida cirúrgica. Foi realizada a cada 24 horas até 72 horas, tanto no GD como no GC, pelos mesmos dois cirurgiões experientes adotando-se os critérios descritos por Pazzini (2014) conforme segue: Avaliações macroscópicas das feridas: consistiam em avaliar a presença ou ausência de exsudato (sendo 0 ausência, 1 discreta presença, 2 moderada presença e 3 intensa presença), edema (sendo 0 ausência, 1 edema discreto, 2 edema moderado e 3 edema intenso) e a integridade da pele consistia em graduar sua coloração (sendo 0 pele normal, 1 hematoma discreto, 2 hematoma moderado e 3 hematoma intenso). Após esta avaliação eram realizadas limpeza da ferida cirúrgica com solução fisiológica e troca de curativo seguido de confecção de bandagem compressiva.

As reavaliações das feridas ocorreram em 14 dias com retirada de pontos (Fig.1F) e em 30 dias para avaliação final da cicatrização, observando-se os critérios descritos acima além de deiscência (sendo 0 ausência, 1 discreta presença, 2 moderada presença 
e 3 intensa presença), fibrose cicatricial (sendo 0 ausência, 1 discreta presença, 2 moderada presença e 3 intensa presença) e necrose (sendo 0 ausência, 1 discreta presença, 2 moderada presença e 3 intensa presença).

Avaliação quantitativa do fluido drenado. No GD realizou-se mensuração do volume total (mL) de fluido drenado a cada 12 horas, após clampeamento do dreno, com o reservatório desinflado e na posição vertical. Devido impossibilidade de mensuração precisa, o volume foi mensurado conforme escore de 0 à 13 (0 nada no reservatório e cânula, 1 nada no reservatório mas presença em cânula ou ranhuras do reservatório, 2 menor que $50 \mathrm{~mL}$, 3 entre 50 e $100 \mathrm{~mL}, 4$ entre 100 e $150 \mathrm{~mL}, 5$ entre 150 e $200 \mathrm{~mL}$, 6 entre 200 e $250 \mathrm{~mL}, 7$ entre 250 e $300 \mathrm{~mL}$, 8 entre 300 e $350 \mathrm{~mL}$, 9 entre 350 e $400 \mathrm{~mL}, 10$ entre 400 e $450 \mathrm{~mL}, 11$ entre 450 e $500 \mathrm{~mL}$, 12 entre 500 e $550 \mathrm{~mL}$ e 13 entre 550 e $600 \mathrm{~mL}$ ) , a cada 12 horas, até a alta hospitalar que ocorreu em 72 horas.

Avaliação qualitativa do fluido drenado. No GD o fluido foi coletado em 24 e 72 horas do reservatório de maneira estéril, com seringa acoplada a sonda urinária e acondicionado em tubo com e sem EDTA. Após envio para o laboratório de análises clínicas da instituição, para análise quanto à celularidade, tipo celular e morfologia celular (citologia). Foram realizados exame físico (cor, aspecto e densidade), exame químico [proteínas $(\mathrm{g} / \mathrm{dL})$, fibrinogênio $(\mathrm{mg} / \mathrm{dL})$, glicose $(\mathrm{mg} / \mathrm{dL})]$, contagem de células totais (eritrócitos/mcL, células nucleadas $/ \mathrm{mcL}$ ), contagem relativa de células nucleadas [neutrófilos (\%), linfócitos (\%), ou macrófagos (\%), eosinófilos (\%)] e avaliação morfológica (citologia) do fluido coletado.

A análise estatística foi realizada com programa computacional SigmaPlot versão 12.0 sendo realizado o teste de Shapiro Wilk para avaliar a ocorrência de distribuição normal dos dados. Para verificação de possíveis diferenças entre tempos dentro do mesmo grupo, utilizou-se a Análise de Variância de Uma Via com Medidas Repetidas no tempo (ANOVA-RM), seguido pelo teste de Dunnet. Para comparação entre os mesmos momentos dos diferentes grupos, utilizou-se o teste $t$. Para comparação entre dois momentos dentro de um mesmo grupo, utilizou-se o teste $t$ pareado. Para avaliação dos dados não paramétricos, como exsudato, integridade da pele, edema, deiscência, fibrose cicatricial, necrose e análise quantitativa de fluido (volume), entre os mesmos momentos dos diferentes grupos utilizou-se Mann Whitney Rank Sum Test, entre dois momentos dentro do mesmo grupo utilizou-se Wilcoxon Signed Rank Test, e entre três momentos ou mais dentro do mesmo grupo utilizou-se Friedman Repeated Measures Analysis of Variance on Ranks, seguido pelo teste de Tukey, considerou-se diferença estatística quando $\mathrm{p} \leq 0,05$.

\section{RESULTADOS E DISCUSSÃO}

0 peso médio, tempo cirúrgico médio e idade média dos animais do GC e GD foi de 17,1 $\pm 9,7 \mathrm{~kg}$ e 12,6 $\pm 8,8 \mathrm{~kg}, 93 \pm 33 \mathrm{~min}$ e $80 \pm 24 \min , 9,3 \pm 2,9$ anos e 9,3 $\pm 2,6$ anos respectivamente, não apresentando diferença significativa entre grupos. 0 tempo cirúrgico não apresentou diferença significativa entre grupos, porém clinicamente o grupo GD apresentou média inferior ao GC, conforme também observado por Papazouglou et al. (2006), sendo que o mesmo observou em um terceiro grupo de seu estudo a utilização de dreno e dermorrafia com grampeadores cirúrgicos seria uma técnica mais rápida. No presente estudo percebemos que um único padrão contínuo no subcutâneo, sem a realização de suturas isoladas proporciona também uma execução mais rápida.

Não foram observadas diferenças significativas nos momentos basal, 24 horas e 72 horas para os valores médios de hemograma (concentração de hemoglobina globular média, proteína plasmática total, plaquetas, neutrófilos bastonetes, linfócitos, eosinófilos, basófilos e monócitos) e bioquímico (ureia, creatinina, colesterol), entre os grupos, bem como entre os momentos dentro de cada grupo (Quadro 1). Houve redução do valor médio de eritrócitos em 72 horas $(5,2 \pm 1,0)$ em relação ao basal $(6,5 \pm 0,9)$ no grupo GD, porém não foram observadas diferenças significativas entre grupos em nenhum dos momentos avaliados. Não foram observadas diferenças significativas dos valores médios de $\mathrm{Hb}$ e hematócrito entre momentos em relação ao basal, porém entre grupos, os valores de $\mathrm{Hb}$ e $\mathrm{Ht}$ foram maiores em 24 horas no GC $(15,1 \pm 1,7$ e 43,5 $\pm 5,7$ respectivamente), quando comparado ao GD $(12,9 \pm 2,5$ e $37 \pm 6,6)$. Houve aumento dos valores médios de VGM em 24 horas $(68,7 \pm 4,9)$ e em 72 horas $(69 \pm 4,5)$ em relação ao basal $(64 \pm 2,1)$ no grupo GD. Não foram observadas diferenças significativas entre grupos em nenhum dos momentos avaliados (Quadro 1). No presente estudo houve redução do número de eritrócitos, hemoglobina e hematócrito em ambos os grupos no pós-operatório em relação ao basal, e isto pode ser explicado pela perda sanguínea decorrente do trans-operatório e a infusão de fluidos no trans e pos-operatório, questão observada por Gonzaléz \& Silva (2008). Thrall et al. (2006) descreveram que o teor plasmático de proteínas diminuem em razão de efeito diluidor decorrente da transferência de fluido intersticial ao sangue.

Conforme Stockham \& Scott (2011) a concentração de eritrócitos, deve ser determinada quando a efusão ou exsudato é rósea a avermelhada, de forma que os valores possam ser comparados com a concentração de eritrócitos ou hematócrito de sangue periférico. A concentração de eritrócitos na maioria das efusões róseas é geralmente muito baixa, sendo $<0,5 \times 10^{6} / \mu \mathrm{L}$, tais valores não representam uma efusão hemorrágica. Hipotetiza-se que a redução nos valores médios de hemoglobina e hematócrito no grupo GD quando comparado ao GC em 24 horas, possa ser explicada pela presença de eritrócitos no exsudato no grupo GD, o qual ficou retido no reservatório.

O volume globular médio (VGM) é um índice eritrocitário que pode estar falsamente diminuído por fenômenos in vitro ou efeitos sobre a osmolalidade (Stockham \& Scott 2011). Isto explica a ocorrência de VGM abaixo dos valores de referências para espécie, os quais geralmente representam processos patológicos. Em oposição, neste estudo observaram-se valores médios menores no basal de VGM quando comparados aos outros momentos no grupo GD, porém apresentavamse dentro dos valores de referência. Acreditamos que esta diferença estatística possa ser explicada por alguns valores mais próximos do limite inferior de referência quando comparados entre momentos, atribuindo assim variação individual, onde não há repercussão hematológica importante.

No leucograma, houve aumento do valor médio

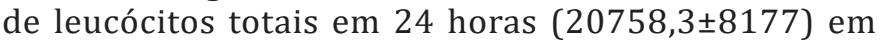
relação ao basal $(10197,8 \pm 2983)$ no grupo GC, sem diferenças significativas entre grupos. Os neutrófilos segmentados foram maiores em 24 horas nos grupos GC e GD $(17167,8 \pm 7123,6$ e 16344,8 $\pm 3798,5$ respectivamente) em relação ao basal $(7054,3 \pm 2350$ e $11950 \pm 6309,8)$, sendo maiores no basal no GD quando comparado ao GC (Quadro 1). As fases de cicatrização de uma lesão de pele suturada incluem migração de neutrófilos para as margens da incisão, resposta 
Quadro 1. Não foram observadas diferenças significativas nos momentos basal, 24 horas e 72 horas para os valores médios e desvio padrão de hemograma das cadelas

\begin{tabular}{|c|c|c|c|c|}
\hline Parâmetros & Grupos & Basal & 24 horas & 72 horas \\
\hline Eritrócitos & $\begin{array}{l}\mathrm{GC} \\
\mathrm{GD}\end{array}$ & $\begin{array}{l}6,5 \pm 0,9 \\
6,5 \pm 0,9\end{array}$ & $\begin{array}{l}6,3 \pm 0,6 \\
5,4 \pm 1,1\end{array}$ & $\begin{array}{c}6 \pm 0,8 \\
5,2 \pm 1,0 \mathrm{~A}\end{array}$ \\
\hline Hemoglobina & $\begin{array}{l}\text { GC } \\
\text { GD }\end{array}$ & $\begin{array}{l}15,7 \pm 2,3 \\
14,8 \pm 1,9\end{array}$ & $\begin{array}{r}15,1 \pm 1,7 \mathrm{a} \\
12,9 \pm 2,5 \mathrm{~b}\end{array}$ & $\begin{array}{l}14,2 \pm 1,7 \\
12,3 \pm 2,1\end{array}$ \\
\hline Hematócrito & $\begin{array}{l}\text { GC } \\
\text { GD }\end{array}$ & $\begin{array}{l}44,4 \pm 5,7 \\
41,8 \pm 6,8\end{array}$ & $\begin{array}{r}43,5 \pm 5,7 \mathrm{a} \\
37 \pm 6,6 \mathrm{~b}\end{array}$ & $\begin{array}{l}40,6 \pm 5,6 \\
35,9 \pm 6,3\end{array}$ \\
\hline VGM & $\begin{array}{l}\text { GC } \\
\text { GD }\end{array}$ & $\begin{array}{r}68,4 \pm 5,8 \\
64 \pm 2,1\end{array}$ & $\begin{array}{l}68,6 \pm 4,9 \\
68,7 \pm 4,9 \mathrm{~A}\end{array}$ & $\begin{array}{l}67,1 \pm 3,4 \\
69 \pm 4,5 \mathrm{~A}\end{array}$ \\
\hline CHGM & $\begin{array}{l}\text { GC } \\
\text { GD }\end{array}$ & $\begin{array}{l}35,6 \pm 2 \\
35,5 \pm 1,3\end{array}$ & $\begin{array}{l}34,8 \pm 1,4 \\
34,9 \pm 1,3\end{array}$ & $\begin{array}{l}34,9 \pm 1,2 \\
34,2 \pm 1,5\end{array}$ \\
\hline PPT & $\begin{array}{l}\text { GC } \\
\text { GD }\end{array}$ & $\begin{array}{l}7,2 \pm 0,4 \\
7,2 \pm 0,7\end{array}$ & $\begin{array}{r}6,9 \pm 0,5 \\
7 \pm 0,5\end{array}$ & $\begin{array}{l}6,6 \pm 0,5 \\
6,6 \pm 0,4\end{array}$ \\
\hline Plaquetas & $\begin{array}{l}\text { GC } \\
\text { GD }\end{array}$ & $\begin{array}{l}391 \pm 140 \\
396 \pm 131\end{array}$ & $\begin{array}{l}349 \pm 81 \\
418 \pm 85\end{array}$ & $\begin{array}{l}335 \pm 76 \\
383 \pm 106\end{array}$ \\
\hline Leucócitos totais & $\begin{array}{l}\text { GC } \\
\text { GD }\end{array}$ & $\begin{array}{l}10197,8 \pm 2983 \\
16632,2 \pm 9235,1\end{array}$ & $\begin{array}{r}20758,3 \pm 8177 \mathrm{~A} \\
19668 \pm 4777,5\end{array}$ & $\begin{array}{l}16439,5 \pm 4901,3 \\
14932,1 \pm 4196,9\end{array}$ \\
\hline Bastonetes & $\begin{array}{l}\text { GC } \\
\text { GD }\end{array}$ & $\begin{array}{c}0 \pm 0 \\
38 \pm 64,4\end{array}$ & $\begin{array}{c}0 \pm 0 \\
59,8 \pm 90,3\end{array}$ & $\begin{array}{c}0 \pm 0 \\
217,7 \pm 653,3\end{array}$ \\
\hline Segmentados & $\begin{array}{l}\text { GC } \\
\text { GD }\end{array}$ & $\begin{array}{l}7054,3 \pm 2350 \mathrm{a} \\
11950 \pm 6309,8 \mathrm{~b}\end{array}$ & $\begin{array}{l}17167,8 \pm 7123,6 \mathrm{~A} \\
16344,8 \pm 3798,5 \mathrm{~A}\end{array}$ & $\begin{array}{l}11985,1 \pm 4043,5 \\
10396,4 \pm 3587,7\end{array}$ \\
\hline Linfócitos & $\begin{array}{l}\text { GC } \\
\text { GD }\end{array}$ & $\begin{array}{l}1753,8 \pm 506 \\
1899,3 \pm 1570,1\end{array}$ & $\begin{array}{l}1622,5 \pm 715 \\
1437,6 \pm 746,8\end{array}$ & $\begin{array}{l}1984,1 \pm 782 \\
1987,8 \pm 1557,3\end{array}$ \\
\hline Eosinófilos & $\begin{array}{l}\text { GC } \\
\text { GD }\end{array}$ & $\begin{array}{c}815,6 \pm 464,9 \\
1601,6 \pm 1727,7\end{array}$ & $\begin{array}{l}982,3 \pm 786,5 \\
519,7 \pm 420,2\end{array}$ & $\begin{array}{l}1128,7 \pm 1142,1 \\
1118,4 \pm 961,7\end{array}$ \\
\hline Basófilos & $\begin{array}{l}\text { GC } \\
\text { GD }\end{array}$ & $\begin{array}{c}10,3 \pm 31 \\
0 \pm 0\end{array}$ & $\begin{array}{l}0 \pm 0 \\
0 \pm 0\end{array}$ & $\begin{array}{l}0 \pm 0 \\
0 \pm 0\end{array}$ \\
\hline Monócitos & $\begin{array}{l}\text { GC } \\
\text { GD }\end{array}$ & $\begin{array}{l}563,7 \pm 397,1 \\
1143,2 \pm 82\end{array}$ & $\begin{array}{c}986 \pm 908,4 \\
1306,2 \pm 1157,5\end{array}$ & $\begin{array}{l}1341,3 \pm 1378,9 \\
1141,6 \pm 503,2\end{array}$ \\
\hline Ureia & $\begin{array}{l}\text { GC } \\
\text { GD }\end{array}$ & $\begin{array}{l}30,2 \pm 19,2 \\
29,5 \pm 15,3\end{array}$ & - & $\begin{array}{l}31,7 \pm 10 \\
38,9 \pm 20\end{array}$ \\
\hline Creatinina & $\begin{array}{l}\text { GC } \\
\text { GD }\end{array}$ & $\begin{array}{l}0,9 \pm 0,3 \\
0,9 \pm 0,2\end{array}$ & - & $\begin{array}{l}0,9 \pm 0,1 \\
0,9 \pm 0,2\end{array}$ \\
\hline Colesterol & $\begin{array}{l}\text { GC } \\
\text { GD }\end{array}$ & $\begin{array}{l}218,9 \pm 47,3 \\
212,9 \pm 62,4\end{array}$ & $\begin{array}{l}- \\
-\end{array}$ & $\begin{array}{l}192,2 \pm 70,3 \\
237,2 \pm 116,7\end{array}$ \\
\hline Triglicérides & $\begin{array}{l}\text { GC } \\
\text { GD }\end{array}$ & $\begin{array}{l}75,4 \pm 19,9 \\
70,2 \pm 33,2\end{array}$ & - & $\begin{array}{l}46,3 \pm 15,4 \mathrm{~A} \\
70,2 \pm 30,7\end{array}$ \\
\hline Glicose & $\begin{array}{l}\text { GC } \\
\text { GD }\end{array}$ & $\begin{array}{l}94,5 \pm 15,9 \\
96,7 \pm 20\end{array}$ & - & $\begin{array}{l}75,8 \pm 10,5 \mathrm{~A} \\
84,3 \pm 16,9\end{array}$ \\
\hline
\end{tabular}

Valores médios e desvio padrão de eritrócitos (x10 $/ \mathrm{mcL}$ ), hemoglobina ( $\mathrm{g} / \mathrm{dL}$ ), hematócrito (\%), volume globular médio (VGM, fL), concentração de hemoglobina globular média (CHGM, \%), proteína plasmática total (PPT, g/dL), plaquetas ( $\left.\mathrm{x} 10^{3} / \mathrm{mcL}\right)$, leucócitos totais (/mcL), neutrófilos bastonetes (Bastonetes/mcL), neutrófilos segmentados (Segmentados/mcL), linfócitos (/mcL), eosinófilos (/mcL), basófilos (/mcL), monócitos (/mcL), ureia $(\mathrm{mg} / \mathrm{dL})$, creatinina $(\mathrm{mg} / \mathrm{dL})$, colesterol $(\mathrm{mg} / \mathrm{dL})$, triglicérides $(\mathrm{mg} / \mathrm{dL})$ e glicose $(\mathrm{mg} / \mathrm{dL})$ em cadelas submetidas à mastectomia unilateral total pela técnica convencional (GC, $\mathrm{n}=9$ ) ou através de colocação de dreno de sucção fechado (GD, n=9). Letras minúsculas diferentes indicam diferença significativa entre grupos; Teste $t(p \leq 0,05)$. Letras maiúsculas indicam diferença significativa em relação ao basal; Anova uma via com repetições múltiplas, seguido de Dunnett $(\mathrm{p} \leq 0,05)$.

inflamatória aguda em cada lado da incisão, ocasionando edema, rubor e dor local (Panobianco et al. 2010). Conforme Williams \& Moores (2013), a inflamação é caracterizada pela migração de leucócitos para o interior da ferida, que ocorre dentro de seis horas após a lesão, iniciando ativação do sistema complemento, o qual recruta neutrófilos que são opsoninas para a fagocitose. Williams \& Moores (2013) ainda citaram que o neutrófilo é a primeira célula a entrar na ferida e o tipo celular predominante durante os três primeiros dias, com pico entre 24 e 48 horas. Isto explica assim o aumento dos leucócitos totais e neutrófilos segmentados nas primeiras 24 horas após a cirurgia no presente estudo.
Estes valores foram normalizados nos dois grupos em 72 horas, comprovando assim o processo fisiológico de cicatrização. Corpos estranhos prejudicam a cicatrização por manterem a reação inflamatória em atividade (Panobianco et al. 2010). Confrontando estes autores, observaram-se maiores valores médios de neutrófilos segmentados e leucócitos no GC que no GD, não sendo observada reação inflamatória celular maior em consequência do dreno.

Para o GD não foram observadas diferenças significativas as 12, 24, 36, 48, 60 e 72 horas no quesito avaliação qualitativa do dreno entre os momentos (Quadro 2), bem como diferenças significativas as 24, 48 e 72 horas no quesito avaliação 
qualitativa da ferida cirúrgica (integridade da pele e edema) entre os grupos, da mesma forma entre os momentos dentro de cada grupo (Quadro 3). Em tempo, não houve diferenças significativas dos valores de mediana de exsudato (avaliação qualitativa da ferida cirúrgica) entre momentos para nenhum dos grupos. Observaram-se valores de medianas significativamente maiores as 24, 48 e 72 horas no GD quando comparado ao GC (Fig.1E, Fig.2, Quadro 4). Para Campbell (2011), a recomendação atual para remoção do dreno é que aconteça o mais cedo possível, baseado em evidências de decréscimo de produção de fluido e platô de volume de fluido. Williams \& Moores (2013) também enfatizaram que drenos ativos devem ser removidos quando a produção de líquidos diminui, e isto ocorre geralmente depois de 2 a 5 dias. A retirada do dreno no presente estudo foi determinada em 72 horas, por observar-se nos estudos pilotos redução importante na produção de fluido. Para Shaver et al. (2014) não existem padrões claros para produção de fluido, tempo de remoção, ou se o peso do animal afeta estas variáveis. Estes autores determinaram que cães que produzem $<0,2 \mathrm{ml} / \mathrm{kg} /$ hora (ou $4,8 \mathrm{ml} / \mathrm{kg} / \mathrm{dia}$ ) de fluido no momento da remoção tem significativamente menos

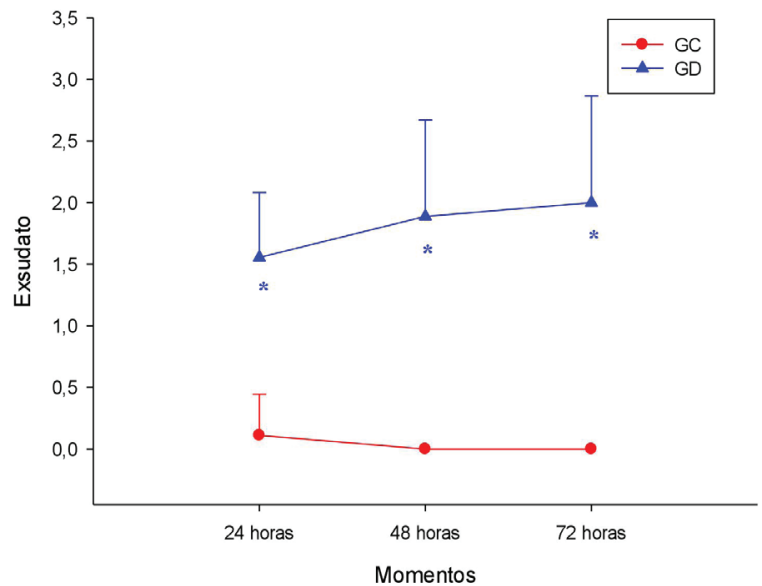

*Significativamente diferente de GC, teste Mann-Whitney Rank Sum Test $(p \leq 0,05)$.

Fig.2. Valores da mediana e erro padrão, de acordo com o escore obtido, em relação à presença ou ausência de exsudato (análise de cicatrização) em 24, 48 e 72 horas em cadelas submetidas à mastectomia unilateral total pela técnica convencional $(\mathrm{GC}, \mathrm{n}=9$ ) ou através de colocação de dreno de sucção fechado (GD, n=9).

Quadro 2. Percentagem e proporção de animais, de acordo com o escore obtido, em relação à análise qualitativa do dreno em cadelas submetidas à mastectomia unilateral total pela técnica de colocação do dreno de sucção fechado (GD, n=9)

\begin{tabular}{ccccccc}
\hline Qual. Dreno & $12 \mathrm{~h}$ & $24 \mathrm{~h}$ & $36 \mathrm{~h}$ & $48 \mathrm{~h}$ & $60 \mathrm{~h}$ & $72 \mathrm{~h}$ \\
\hline Escore 0 & $77,7 \%(7 / 9)$ & $100 \%(9 / 9)$ & $100 \%(9 / 9)$ & $100 \%(9 / 9)$ & $100 \%(9 / 9)$ & $100 \%(9 / 9)$ \\
Escore 1 & $2 / 9$ & $0 / 9$ & $0 / 9$ & $0 / 9$ & $0 / 9$ & $0 / 9$ \\
Escore 2 & $0 / 9$ & $0 / 9$ & $0 / 9$ & $0 / 9$ & $0 / 9$ & $0 / 9$ \\
Escore 3 & $0 / 9$ & $0 / 9$ & $0 / 9$ & $0 / 9$ & $0 / 9$
\end{tabular}

Escore 0 = nenhum desconforto, Escore 1 = moderada irritação (tenta remover o dreno), Escore 2 = moderadamente doloroso ("uiva", recua ao contato), Escore 3 = dor acentuada (grita, tenta morder ou fugir).

Quadro 3. Percentagem e proporção de animais, de acordo com o escore obtido, em relação à integridade da pele (análise de cicatrização) e presença ou ausência de edema (análise de cicatrização) em 24,48 e 72 horas em cadelas submetidas à mastectomia unilateral total pela técnica convencional $(\mathrm{GC}, \mathrm{n}=9)$ ou através de colocação de dreno de sucção fechado (GD, $n=9)$

\begin{tabular}{|c|c|c|c|c|}
\hline Int. pele & Grupos & 24 horas & 48 horas & 72 horas \\
\hline Escore 0 & $\begin{array}{l}\text { GC } \\
\text { GD }\end{array}$ & $\begin{array}{l}44,4 \%(4 / 9) \\
55,5 \%(5 / 9)\end{array}$ & $\begin{array}{l}22,2 \%(2 / 9) \\
44,4 \%(4 / 9)\end{array}$ & $\begin{array}{l}55,5 \%(5 / 9) \\
55,5 \%(5 / 9)\end{array}$ \\
\hline Escore 1 & $\begin{array}{l}\text { GC } \\
\text { GD }\end{array}$ & $\begin{array}{l}55,5 \%(5 / 9) \\
11,1 \%(1 / 9)\end{array}$ & $\begin{array}{l}55,5 \%(5 / 9) \\
33,3 \%(3 / 9)\end{array}$ & $\begin{array}{l}44,4 \%(4 / 9) \\
33,3 \%(3 / 9)\end{array}$ \\
\hline Escore 2 & $\begin{array}{l}\text { GC } \\
\text { GD }\end{array}$ & $\begin{array}{c}0 / 9 \\
22,2 \%(2 / 9)\end{array}$ & $\begin{array}{l}22,2 \%(2 / 9) \\
11,1 \%(1 / 9)\end{array}$ & $\begin{array}{c}0 / 9 \\
11,1 \%(1 / 9)\end{array}$ \\
\hline Escore 3 & $\begin{array}{l}\text { GC } \\
\text { GD }\end{array}$ & $\begin{array}{c}0 / 9 \\
11,1 \%(1 / 9)\end{array}$ & $\begin{array}{c}0 / 9 \\
11,1 \%(1 / 9)\end{array}$ & $\begin{array}{l}0 / 9 \\
0 / 9\end{array}$ \\
\hline Escore 0 & $\begin{array}{l}\text { GC } \\
\text { GD }\end{array}$ & $\begin{array}{l}66,6 \%(6 / 9) \\
100 \%(9 / 9)\end{array}$ & $\begin{array}{l}88,8 \%(8 / 9) \\
100 \%(9 / 9)\end{array}$ & $\begin{array}{l}100 \%(9 / 9) \\
100 \%(9 / 9)\end{array}$ \\
\hline Escore 1 & $\begin{array}{l}\text { GC } \\
\text { GD }\end{array}$ & $\begin{array}{c}33,3 \%(3 / 9) \\
0 / 9\end{array}$ & $\begin{array}{c}11,1 \%(1 / 9) \\
0 / 9\end{array}$ & $\begin{array}{l}0 / 9 \\
0 / 9\end{array}$ \\
\hline Escore 2 & $\begin{array}{l}\text { GC } \\
\text { GD }\end{array}$ & $\begin{array}{l}0 / 9 \\
0 / 9\end{array}$ & $\begin{array}{l}0 / 9 \\
0 / 9\end{array}$ & $\begin{array}{l}0 / 9 \\
0 / 9\end{array}$ \\
\hline
\end{tabular}

Int. pele: Escore 0 = pele normal, Escore 1 = hematoma discreto, Escore 2 = hematoma moderado, Escore 3 = hematoma intenso; Edema: Escore 0 = ausência, Escore 1 = edema discreto, Escore 2 = edema moderado, Escore 3 = edema intenso. 
Quadro 4. Valores da mediana e erro padrão, de acordo com o escore obtido, em relação à presença ou ausência de exsudato (análise de cicatrização) em 24, 48 e 72 horas em cadelas submetidas à mastectomia unilateral total pela técnica convencional (GC, $n=9)$ ou através de colocação de dreno de sucção fechado (GD, n=9)

\begin{tabular}{cccc}
\hline Grupos & 24 horas & 48 horas & 72 horas \\
\hline GC & $0 \pm 0,1 \mathrm{a}$ & $0 \pm 0 \mathrm{a}$ & $0 \pm 0 \mathrm{a}$ \\
GD & $2 \pm 0,2 \mathrm{~b}$ & $2 \pm 0,3 \mathrm{~b}$ & $2 \pm 0,3 \mathrm{~b}$
\end{tabular}

Letras minúsculas diferentes indicam diferença significativa entre grupos; Mann-Whitney Rank Sum Test $(\mathrm{p} \leq 0,05)$

formação de seroma, sugerindo que isto possa ser utilizado como referência para retirada de drenos.

Estes autores utilizaram o dreno de sucção fechada Jackson-Pratt ${ }^{\circledR}$, o qual possui frasco coletor oval sem ser corrugado, e o utilizaram em diversos procedimentos, incluindo mastectomias, cirurgias reconstrutivas, ressecção de parede torácica, hemipelvectomia, sialodenectomia, linfadenectomia e exéreses de massas tumorais. Por se tratar de um estudo restrospectivo, acredita-se que a diversidade de procedimentos possam gerar diferentes taxas diárias de fluido, gerando limitações nas comparações. Williams \& Moores (2013) afirmaram que há pouca informação na literatura veterinária sobre produção de líquidos por drenagem, mas sugerem como prática comum a remoção do dreno, quando a produção de líquidos estiver $<2$ a $4 \mathrm{ml} / \mathrm{kg} /$ dia, já que se espera que essa quantidade seja produzida pela reação inflamatória causada pela presença do dreno na ferida.

No presente estudo a mensuração do líquido diária não ocorreu de maneira exata como no estudo proposto com dreno Jackson-Pratt, por se tratar de dreno com frasco coletor corrugado, e escalas de mensuração a cada $50 \mathrm{ml}$. Porém, com estimativas do volume, foi possível observar redução no volume diário em 48 e 60 horas, não ultrapassando a produção de líquidos de $4 \mathrm{ml} / \mathrm{kg} /$ dia e $4,8 \mathrm{ml} / \mathrm{kg} /$ dia sugeridos por Williams \& Moores (2013) e Shaver et al. (2014) respectivamente.

Shaver et al. (2014), observaram que 8 de 57 (14\%) cães formaram seroma, e estes possuíram drenos removidos quando a produção apresentava-se $<0,2 \mathrm{ml} / \mathrm{kg} / \mathrm{h}$, mostrando que mesmo uma pequena parcela da amostra pode apresentar esta complicação, explicando assim a ocorrência de seroma no pós-operatório em 2 dos 9 animais do grupo GD do presente estudo, que sofreram retirada do dreno em 72 horas. Em contrapartida, Barton et al. (2006) citaram que a remoção precoce do dreno aumenta significativamente a ocorrência de seroma requerendo tratamento adicional, acrescentando que estes não devem ser removidos antes de dois dias. Apesar de ter sido um fato isolado, isto pode explicar a ocorrência de seroma e necessidade de punção com agulha aos 14 dias no animal que removeu o dreno antes de 48 horas. Barwell et al. (1997) acrescentam que 74\% do volume total drenado de uma ferida ocorre nas primeiras 48 horas após a cirurgia, mostrando a importância da permanência do dreno neste período.

Conforme Kuroi et al. (2006b) e Agrawal et al. (2006) nenhum consenso foi atingido em relação à pressão de aspiração ótima, número de drenos ou tempo de drenagem para evitar complicações pós-operatórias em mastectomias em mulheres.
Mais recentemente Williams \& Moores (2013) determinaram que a quantidade de vácuo que deve ser colocada no dreno deve ser suficiente para eliminar o espaço morto, mas não deve ser tão alta a ponto de causar lesão tecidual. Halfacree et al. (2006) já haviam sugerido em um estudo in vitro que em drenos compressíveis manuais, a compressão realizada com as duas mãos resulta em pressão negativa significativamente maior quando comparada com a compressão com uma mão. No presente estudo piloto observou-se que a pressão adequada era mantida quando a compressão era realizada com as duas mãos em intervalo de 12 em 12 horas, sendo que o primeiro vácuo foi sempre realizado 6 horas após o término do procedimento cirúrgico, corroborando com Williams \& Moores (2013) os quais citaram que o sistema coletor não deve ser aberto até que uma capa de fibrina tenha se formado sobre a ferida, ou seja, após 4 a 6 horas.

Não foram observadas, diferenças significativas aos $14 \mathrm{e}$ 30 dias de avaliação qualitativa de ferida cirúrgica (exsudato, integridade da pele, fibrose cicatricial, deiscência e necrose), entre grupos, bem como entre momentos dentro de cada grupo. Dois animais do grupo GD, apresentaram fibrose cicatricial, um animal no qual utilizou-se cânula de $6,4 \mathrm{~mm}$ observou-se moderada fibrose cicatricial em 14 e 30 dias, já no outro animal utilizou-se cânula de $4,8 \mathrm{~mm}$ e observou-se discreta fibrose cicatricial apenas em 30 dias. Anteriormente os drenos eram tradicionalmente fabricados em borracha, o que causava reações inflamatórias marcantes, por isso atualmente são produzidos por materiais inertes (Williams \& Moores 2013). Muitos fatores podem reduzir, retardar ou impedir a cicatrização, entre eles fatores sistêmicos como infecções ou fatores locais como corpos estranhos, os quais podem manter a reação inflamatória em atividade (Panobianco et al. 2010). Acredita-se que a presença de mais de um dreno ou um dreno de diâmetro maior possa contribuir para uma resposta inflamatória maior, e consequentemente uma fase de reparação e maturação cicatricial exacerbadas. Devido a uma amostra pequena neste estudo ( $\mathrm{n}=9$ ), não se pode afirmar se a reação cicatricial está realmente associada ao tamanho e/ou quantidade de drenos, ou se está relacionado a fatores intrínsecos do animal, desta forma, mais estudos em medicina veterinária são necessários.

$\mathrm{Na}$ análise quantitativa do fluido drenado (volume) houve aumento dos valores de mediana de fluido drenado em 60 e 72 horas em relação às 12 horas no grupo GD (Quadro 5). A coleta de fluido foi possível apenas no grupo GD, sendo que não foram observadas diferenças significativas em 24 e 72 horas, para os valores médios de avaliação qualitativa do fluido drenado (proteína, glicose, eritrócitos, células nucleados, eosinófilos e macrófagos), da mesma forma os parâmetros de cor e aspecto (exame físico) do fluido drenado não sofreram variação entre indivíduos. A análise da morfologia celular (citologia) do fluido drenado foi similar entre os indivíduos, com características normais para o tipo de fluido analisado, apresentando eritrócitos íntegros e lisados, neutrófilos segmentados e hipersegmentados e células em picnose. Houve aumento dos valores médios de densidade, neutrófilos e linfócitos, e aumento do valor de mediana e erro padrão de fibrinogênio em 72 horas em relação às 24 horas no grupo GD (Quadro 6). Conforme Stockham \& Scott (2011) um exsudato forma-se quando uma inflamação provoca aumento de permeabilidade vascular que permite ao plasma 
Quadro 5. Valores da mediana e erro padrão, de acordo com o escore obtido, em relação à análise quantitativa do fluido drenado (volume) em 12, 24, 36, 48, 60 e 72 horas em cadelas submetidas à mastectomia unilateral total com colocação de dreno de sucção fechado (GD, n=9)

\begin{tabular}{cccccc}
\hline $12 \mathrm{~h}$ & $24 \mathrm{~h}$ & $36 \mathrm{~h}$ & $48 \mathrm{~h}$ & $60 \mathrm{~h}$ & $72 \mathrm{~h}$ \\
\hline $2 \pm 0,34$ & $2 \pm 0,34$ & $2 \pm 0,3$ & $3 \pm 0,5$ & $3 \pm 0,5 \mathrm{~A}$ & $3 \pm 0,6 \mathrm{~A}$
\end{tabular}

Letras maiúsculas indicam diferença significativa em relação à 12 horas; Friedman Repeated Measures Anova on Ranks, seguido de Tukey $(\mathrm{p} \leq 0,05)$.

Quadro 6. Valores médios e desvio padrão de análise do líquido subcutâneo proteínas $(\mathrm{g} / \mathrm{dL})$, glicose $(\mathrm{mg} / \mathrm{dL})$, eritrócitos $(/ \mathrm{mcL})$, células nucleadas $(/ \mathrm{mcL})$, macrófagos (\%), eosinófilos (\%), densidade, fibrinogênio (mg/dL), neutrófilos (\%) e linfócitos $(\%)$ em cadelas submetidas à mastectomia unilateral total pela técnica de colocação de dreno (GD, n=9)

\begin{tabular}{ccc}
\hline & 24 horas & 72 horas \\
\hline Proteína & $2,4 \pm 2,9$ & $5,2 \pm 1,7$ \\
Glicose & $22,4 \pm 31,6$ & $51,8 \pm 34,2$ \\
Eritrócitos & $388100 \pm 630170,8$ & $502861 \pm 499735,4$ \\
Cél. nucleadas & $51070 \pm 147535,6$ & $7648,8 \pm 8417,8$ \\
Macrófagos & $2,7 \pm 3,5$ & $8,8 \pm 7,3$ \\
Eosinófilos & $0,4 \pm 1$ & $0,3 \pm 1$ \\
Densidade & $0,5 \pm 0,5$ & $1 \pm 0,01 \mathrm{~A}$ \\
Fibrinogênio & $0,4 \pm 0,5$ & $1,5 \pm 1 \mathrm{~A}$ \\
Neutrófilos & $39,1 \pm 46,50$ & $84,4 \pm 8, \mathrm{~A}$ \\
Linfócitos & $2,1 \pm 3,3$ & $6,5 \pm 3,3 \mathrm{~A}$
\end{tabular}

Letra maiúscula indica diferença significativa em relação à 24 horas; Teste t pareado $(\mathrm{p} \leq 0,05)$.

e suas proteínas exsudar do sangue, sendo esta exsudação acompanhada de células nucleadas, mais comumente composta por neutrófilos, ou uma mistura de neutrófilos, macrófagos e linfócitos, e ocasionalmente presença de eosinófilos. Corroborando com Stockham \& Scott (2011) estas células nucleadas foram encontradas na análise citológica do fluido do presente estudo, com uma maior quantidade de neutrófilos, seguido de linfócitos e macrófagos, e apenas dois animais do grupo GD com presença de eosinófilos.

O fibrinogênio é uma proteína da fase aguda positiva produzida pelos hepatócitos, e que aumenta no plasma durante exercício e na inflamação (Stockham \& Scott 2011). Representa uma grande porção da proteína plasmática, presente em resposta da fase aguda (Kaneko et al. 2008). Como no exsudato naturalmente há presença de proteínas, fibrinogênio, neutrófilos e linfócitos, acredita-se que o aumento de seus valores médios em 72 horas em relação às 24 horas, seja explicado pelo fato de não esvaziarmos os reservatórios a cada avaliação, levando um acúmulo de fluido, e consequentemente células. Stockham \& Scott (2011) citaram que como a densidade é mensurada com refratômetro, e à medida que um soluto é adicionado em solução, a intensidade em que a luz diminui sua velocidade e sofre refração aumenta proporcionalmente com o aumento na concentração de soluto, levando assim aumento na densidade. Isto explica a densidade aumentada em 72 horas, em consequência ao maior número de células, ou seja, soluto em solução.
Foram utilizados neste estudo 18 animais, provenientes da rotina clínica do Hospital Veterinário, pertencentes à raça Boxer (1), Labrador (1), Cocker Spaniel (1), Pointer (2), Dachshund (2), Shih-Tzu (1) e sem raça definida (10). Quatro animais foram excluídos do estudo por removerem precocemente o dreno. Dois animais excluídos faziam parte do estudo piloto. No primeiro estudo piloto foi realizada mastectomia unilateral total com uso de dois drenos no leito cirúrgico, e saída em região caudo-lateral à ferida, porém o animal removeu o dreno em 8 horas de pós-operatório, e apresentou fibrose cicatricial em 14 e em 30 dias. Após a última avaliação deste paciente foi realizada biópsia da cicatriz, comprovando histopatologicamente hiperplasia cicatricial. Com base neste achado, no segundo animal do estudo piloto foi realizada mastectomia unilateral total com uso de dreno simples, mas ainda com saída em região caudo-lateral à ferida, sendo que o dreno também foi removido precocemente pelo animal em 36 horas de pós-operatório. Desta forma, após este último estudo piloto estabeleceu-se a colocação de dreno simples, porém com saída em região crânio-medial à ferida cirúrgica, acreditando-se que neste local seria menos desconfortável, e foi também associada à utilização de suporte para acomodação do dreno, conforme descrito anteriormente. Os outros dois animais que foram excluídos durante o estudo, também removeram o dreno precocemente, porém um deles possuía comportamento agitado, e o outro se agitou durante a troca de curativo, ocasionando a remoção acidental do dreno em 29 e 48 horas respectivamente. 0 animal que removeu o dreno com 29 horas apresentou seroma em 14 dias de pós-operatório.

A colocação e manejo de drenos não são bem relatados na medicina veterinária, e geralmente a determinação de seu uso, tipo de dreno e tempo de permanência são baseados na experiência de cada profissional (Shaver et al. 2014), reforçando assim a relevância em realizar-se estudos sobre utilização de drenos em cirurgias envolvendo animais, neste sentido não podemos afirmar que a remoção precoce do dreno no primeiro estudo piloto ocorreu pelo desconforto gerado pela utilização de duas cânulas do dreno na ferida cirúrgica. Neste sentido, Saratzis et al. (2009) estabeleceram que o uso de um dreno em mulheres é tão efetivo quanto a utilização de dois ou três drenos, no contexto formação de seroma, demonstrando que o uso de mais de um dreno pode causar desconforto, distúrbios do sono no período pós-operatório e internamento hospitalar prolongado. Desta forma, a partir desta remoção precoce, optou-se pela técnica com dreno único nos demais animais do estudo.

Alguns cirurgiões têm optado por aproximações não convencionais em mastectomias de cadelas para eliminar espaço morto, inserindo drenos subcutâneos em vez de grande quantidade de materiais de sutura (Wilson \& Hayes 1983). Mais recentemente, Williams \& Moores (2013) reforçaram a ideia de que para feridas longas, a utilização de uma sutura simples contínua deve ser considerada, pois ajuda a espalhar a tensão uniformemente e reduz o risco de atar muitos nós individuais, explicando assim a utilização no presente estudo da associação do dreno de sucção fechado e redução do subcutâneo em único padrão, com sutura contínua simples em mastectomias.

Os drenos cirúrgicos são comumente utilizados em procedimentos de tecidos moles para prevenir acúmulo de bolsões de fluido, que podem predispor a infecção, deiscência, 
retardo na cicatrização e desconforto (Campbell 2011). Divino et al. (2000) e Somers et al. (1992) citaram que drenos também facilitam a cicatrização por promover aderência de flapes cutâneos na parede torácica, julgando importante sua utilização. Corroborando com este estudo, observou-se boa aderência cutânea nas feridas cirúrgicas de mastectomias com uso do dreno.

Embora os drenos tenham sido usados em mastectomias em muitos centros, seus benefícios têm sido questionados e seu papel tornou-se controverso (Zavotsky et al. 1998, Talbot \& Magarey 2002, Jain et al. 2004, Kuroi et al. 2006a). Parker et al. (2007) concluíram que há evidência suficiente para recomendar rotineiramente a utilização de drenos de sucção fechados para cirurgias ortopédicas. He et al. (2011) afirmaram que a inserção de drenos resultam em redução significativa na taxa de seroma, volume de aspiração ou frequência de aspiração de seroma, diferente do que observamos no presente estudo. Em contrapartida, Troost et al. (2015) afirmaram que não há diferenças na formação de seroma ou suas complicações após cirurgias de mama em mulheres, entre pacientes que possuíam drenagem pós-operatória e pacientes que não possuíam este recurso, corroborando com o observado no presente estudo, onde observou-se também uma maior quantidade de exsudato na presença do dreno quando comparado ao grupo convencional, podendo ser explicado pelo fato que o dreno estimule uma reação inflamatória maior e predisponha a formação de seroma (Shaver et al. 2014).

Dois animais do grupo GD apresentaram formação de seroma após a retirada do dreno, sendo que em um deles foi realizada punção com agulha e remoção de $5 \mathrm{ml}$ de seroma na retirada de pontos. Na avaliação de 30 dias do mesmo animal, a ferida cirúrgica apresentava-se normal. 0 segundo animal retornou ao Hospital Veterinário em 4 dias após a alta por apresentar prostração, hiporexia, êmese e secreção vaginal. Neste retorno foram realizados exames complementares por se suspeitar de piometra, porém os exames apresentaram-se normais. A cicatrização apresentava seroma em ferida caudal, e este foi removido através de punção com agulha. Foi prescrito omeprazol $1 \mathrm{mg} / \mathrm{kg}$ SID por 10 dias e manutenção da cefalexina pós-operatória. Dois dias após, animal retornou apresentando melhora clínica, porém foram removidos mais $150 \mathrm{ml}$ de seroma, na retirada de pontos aos 14 dias a ferida cirúrgica apresentava-se normal sem presença de seroma, mas segundo proprietário o animal havia apresentado um episódio de descarga vaginal fétida. Já na avaliação de 30 dias, a ferida cirúrgica apresentava-se normal, e a paciente foi encaminhada para ovariossalpingohisterectomia terapêutica.

\section{CONCLUSÕES}

A colocação de dreno de sucção fechado apresenta maior teor de exsudato, com redução dos eritrócitos 72 horas após sua colocação, em comparação à técnica convencional.

Recomenda-se que o vácuo do dreno seja refeito de 12 em 12 horas, sendo inicialmente realizado 6 horas após o término da cirurgia.

0 dreno deve ser removido 72 horas após o término da cirurgia, quando a produção de fluido diminui. A presença do dreno de sucção fechado não gera desconforto adicional ao paciente, porém após sua retirada, houve formação de seroma em $22,2 \%$ das cadelas.
A técnica de dreno de sucção fechada é uma alternativa viável à técnica convencional, no entanto, necessita de acompanhamento criterioso e monitoração constante das funções do paciente.

\section{REFERÊNCIAS}

Agrawal A., Ayantunde A.A. \& Cheung K.L. 2006. Concepts of seroma formation and prevention in breast cancer surgery. 2006. ANZ J. Surg. 76(12):1088-1095. <http://dx.doi.org/10.1111/j.1445-2197.2006.03949.x><PMid:17199696>

Barton A., Blitz M., Callahan D., Yakimets W., Adams D. \& Dabbs K. 2006. Early removal of postmastectomy drains is not beneficial: results from a halted randomized controlled trial. Am. J. Surg. 191(5):652-656. <http://dx.doi. org/10.1016/j.amjsurg.2006.01.037><PMid:16647354>

Barwell J., Campbell L., Watkins R.M. \& Teasdale C. 1997. How long should suction drains stay in after breast surgery with axillary dissection? Ann. R. Coll. Surg. Engl. 79(6):435-437. <PMid:9422871>

Campbell B.G. 2011. Bandages and drains, p.221-230. In: Johnston S.A.\& Tobias K.M. (Eds), Veterinary Surgery: small animal. Vol.2. W.B. Saunders, St Louis.

Cassali G., Lavalle G.E., De Nardi A.B., Ferreira E. \& Bertagnolli A.C. 2011. Consensus for the diagnosis, prognosis and treatment of canine mammary tumors. Braz. J. Vet. Pathol. 4(2):153-180.

Demaria M., Stanley B.J., Hauptman J.G., Steficek B.A., Fritz M.C., Ryan J.M., Lam N.A., Moore T.W. \& Hadley H.S. 2011. Effects of negative pressure wound therapy on healing of open wounds in dogs. Vet. Surg. 40(6):658-669. <http://dx.doi.org/10.1111/j.1532-950X.2011.00849.x><PMid:21770975>

Divino C.M., Kuerer H.M. \& Tartter P.I. 2000. Drains prevent seromas following lumpectomy with axillary dissection. Breast J. 6(1):31-33. <http://dx.doi org/10.1046/j.1524-4741.2000.99037.x> <PMid:11348332>

Dougherty S.H. \& Simmons R.L. 1992. The biology and practice of surgical drains. II. Curr. Probl. Surg. 29(9):633-730.<http://dx.doi.org/10.1016/00113840(92)90028-2><PMid:1424760>

González F.H.D. \& Silva S.C. 2008. Patologia Clínica Veterinária: texto introdutório. Universidade Federal do Rio Grande do Sul, Porto Alegre, p.290-296.

Halfacree Z.J., Wilson A. \& Baines S.J. 2006. In vitro performance of active suction drains. 35rd Symposium of the American College of Veterinary Surgeons. p.35:E9-E10. (Abstract)

Harvey H.J. 1996. Glândulas mamárias, p.425-429. In: Bojrab M.J. (Ed), Técnicas Atuais em Cirurgia de Pequenos Animais. 4aㅡ ed. Roca, São Paulo.

He X.D., Guo Z.H., Tian J.H., Yang K.H. \& Xie X.D. 2011. Whether drainage should be used after surgery for breast cancer? A systematic review of randomized controlled trails. Med. Oncol. 28(S1):22-30. <http://dx.doi. org/10.1007/s12032-010-9673-2>

Jain P.K., Sowdi R., Anderson A.D. \& MacFie J. 2004. Randomized clinical trial investigating the use of drains and fibrin sealant following surgery for breast cancer. Brit. J. Surg. 91(1):54-60. <http://dx.doi.org/10.1002/ bjs.4435><PMid:14716794>

Kaneko J.J., Harvey J.W. \& Bruss M.L. 2008. Clinical Biochemistry of Domestic Animals. 6th ed. Academic Press, San Diego, p.135-141.

Kumar S., Lal B. \& Misra M.C. 1995. Post-mastectomy seroma: a new look into the aetiology of an old problem. J. R. Coll. Surg. Engl. 40(5):292-294 $<$ PMid:8523301>

Kuroi K., Shimozuma K., Taguchi T., Imai H., Yamashiro H., Ohsumi S. \& Saito S. 2006a. Evidence-based risk factors for seroma formation in breast surgery. Jpn. J. Clin. Oncol. 36(4):197-206. <http://dx.doi.org/10.1093/ jjco/hyl019><PMid:16684859>

Kuroi K., Shimozuma K., Taguchi T., Imai H., Yamashiro H., Ohsumi S. \& Saito S. 2006b. Effect of mechanical closure of dead space on seroma formation after breast surgery. Breast Cancer 13(3):260-265. <http:// dx.doi.org/10.2325/jbcs.13.260><PMid:16929119> 
Panobianco M.S., Sampaio B.A.L., Caetano E.A., Inocenti A. \& Gozzo T.O. 2010 Comparação da cicatrização pós-mastectomia entre mulheres portadoras e não-portadoras de diabetes mellitus. Revta Rede Enfermagem Nordeste 11:15-22.

Papazouglou L., Tsioli V., Karayannopoulou M., Savvas I., Kazakos G. \& Kaldrymidou-Koutalianou E. 2006. Comparison of three methods for closure of mastectomy in dogs. Aust. Vet. Pract. 36(4):156-162.

Parker M.J., Livingstone V., Clifton R. \& McKee A. 2007. Closed suction surgical wound drainage after orthopaedic surgery. Cochrane Database Syst. Rev. 4(3):1-50. <PMid:17636687>

Pazzini J.M. 2014. Plasma rico em plaquetas empregado a cirurgia reconstrutiva em coelhos (Oryctolagus cuniculus): avaliação da exequibilidade da técnica, achados macroscópicos e histopatológicos. Dissertação de Mestrado em Ciência Animal, Universidade Estadual Paulista, Faculdade de Ciências Agrárias e Veterinárias, Jaboticabal. 104p.

Saratzis A., Soumian S., Willetts R., Rastall S. \& Stonelake P.S. 2009. Use of multiple drains after mastectomy is associated with more patient discomfort and longer postoperative stay. Clin. Breast Cancer 9(4):243-246. <http:// dx.doi.org/10.3816/CBC.2009.n.041><PMid:19933080>

Shaver S.L., Hunt G.B. \& Kidd S.W. 2014. Evaluation of fluid production and seroma formation after placement of closed suction drains in clean subcutaneous surgical wounds of dogs: 77 cases (2005-2012). J. Am. Vet. Med. Assoc. 245(2):211-215. <http://dx.doi.org/10.2460/javma.245.2.211> $<$ PMid:24984132>

Sleeckx N., Rooster H., Veldhuis Kroeze E.J., Van Ginneken C. \& Van Brantegem L. 2011. Canine mammary tumours, an overview. Reprod. Domest. Anim. 46(6):1112-1131. <http://dx.doi.org/10.1111/j.1439-0531.2011.01816. $\mathrm{x}><$ PMid:21645126>

Somers R.G., Jablon L.K., Kaplan M.J., Sandler G.L. \& Rosenblatt N.K. 1992. The use of closed suction drainage after lumpectomy and axillary node dissection for breast cancer: a prospective randomized trial. Ann. Surg 215(2):146-149. <http://dx.doi.org/10.1097/00000658-19920200000009> <PMid:1546900>
Sorenmo K.U., Kristiansen V.M., Cofone M.A., Shofer F.S., Breen A.M., Langeland M., Mongil C.M., Grondahl A.M., Teige J. \& Goldschmidt M.H. 2009. Canine mammary gland tumours; a histological continuum from benign to malignant; clinical and histopathological evidence. Vet. Comp. Oncol. 7(3):162-172. <http://dx.doi.org/10.1111/j.1476-5829.2009.00184.x> <PMid:19691645>

Stockham S.L. \& Scott M.A. 2011. Efusões cavitárias, p.697-704. In: Stockham S.L. \& Scott M.A. (Eds), Fundamentos da Patologia Clínica Veterinária. Guanabara Koogan, Rio de Janeiro.

Talbot M.L. \& Magarey C.J. 2002. Reduced use of drains following axillary lymphadenectomy for breast cancer. ANZ J. Surg. 72(7):488-490. <http:// dx.doi.org/10.1046/j.1445-2197.2002.02456.x> <PMid:12123509>

Thrall A.M., Weiser G., Allison R.W. \& Campbell T.W. 2006. Anemia regenerativa, p.74-96. In: Thrall A.M., Weiser G., Allison R.W. \& Campbell T.W. (Eds), Hematologia e Bioquímica Clínica Veterinária. Roca, São Paulo.

Troost M.S., Kempees C.J. \& Roos M.A. 2015. Breast cancer surgery without drains: no influence on seroma formation. J. Surg 13:170-174. <PMid:25486263>

Williams J. \& Moores A. 2013. Manual de Feridas de Cães e Gatos. 2ª ed. Roca, São Paulo.

Wilson G.P. \& Hayes H.M. 1983. Ovariohysterectomy in the dog and cat, p.334337. In: Bojrab M.J. (Eds), Current Techniques in Small Animal Surgery. 2nd ed. Lea and Febiger, Philadephia.

Withrow S.J. 2013. Why worry about cancer in pets? p.15-16. In: Withrow S.J., Vail D.M. \& Page R. (Eds), Small Clinical Oncology. Saunders Elsevier, St Louis. <http://dx.doi.org/10.1016/B978-1-4377-2362-5.00040-2>.

Zavotsky J., Jones R.C., Brennan M.B. \& Giuliano A.E. 1998. Evaluation of axillary lymphadenectomy without axillary drainage for patients undergoing breast-conserving therapy. Ann. Surg. Oncol. 5(3):227-231. <http://dx.doi. org/10.1007/BF02303777> <PMid:9607623> 